\title{
Relationship Between Flexed Posture, Physical Performance and the Functional Status Level in the Elderly
}

\author{
Halfi Farmasari, Wanarani Alwin \\ Department of Physical Medicine and Rehabilitation, Faculty of Medicine University of Indonesia
}

\begin{abstract}
Objectives : To provide a description of the severity of flexed posture, physical performance and functional status level in the elderly and to investigate the relationship between flexed posture (FP), physical performance and the functional status level in the elderly.

Methods : One hundred and eight elders ( 60-90 year-old) with flexed posture were assessed in Geriatric and Physical Medicine and Rehabilitation Outpatient Clinics Hasan Sadikin Hospital Bandung from July until August 2010. Clinical assessment included the severity of FP( standing occipital to wall distance - OWD, demographic (age, gender, education, marital status, occupation), Body Mass Index (BMI), clinical profile ( Mini-Mental State Examination, Geriatric Depression Scale), Physical performance ( Short Physical Performance Battery - SPPB) and evaluation of disability ( Barthel index and Nottingham Extended Activities of Daily Living index - NADL index ) Study design is: cross sectional study.

Results : The mean age of the subjects was $72.21(6.69)$ and $68(63.0 \%)$ were women. The severity of FP was classified as mild in $31(28.7 \%)$, moderate in $50(46.3 \%)$ and severe in 27 patients $(25.05 \%)$. Physical performance was measured by SPPB median 8 (3-12). Disability or functional status level were measured by the Barthel index median 95 (65-100) and NADL index median 53 (12-63).

The severe FP group was significantly different the from mild and moderate group in the clinical profile (greater depression and MMSE). Increased severity of FP was related to decline physical performance (SPPB) $(p<0.001)$ and disability, Barthel index $(p<0.001)$ and NADL index $(p<0.001)$ in the elderly. Conclusions : Severity of flexed posture is related to declined physical performance and functional status level in elderly.
\end{abstract}

Keywords: Elderly, Flexed posture, SPPB, Barthel index, NADL index.

\section{INTRODUCTION}

The aging process characteristically modifies normal postural alignment, and flexed posture (FP) frequently occurs. ${ }^{1}$ Thoracic kyphosis,

Received in March 2012 and accepted for published in April 2012.

Correspondence address : Halfi Farmasari, RS Hermina Arcamanik J1. AH Nasution Km.7 no.50, Bandung 40291 ; Email: farmasarihf@ymail.com protruded head, and in more severe cases hip flexion, knee flexion, ankle dorsiflexion and a wider base of support characterize FP. ${ }^{1-5}$ Pathophysiology of FP in the elderly is poorly understood but most likely multifactorial.1 Most of previous studies have been focused on the association between kyphosis and low bone mineral density (BMD), and consequently vertebral fractures, but it may also result from non-osteoporotic conditions such as comorbid condition and deconditioning. Intervertebral 
disks undergo the most dramatic age-related changes of all connective tissue which can cause kyphosis. Decreased muscle strength can also cause kyphosis. Back extensor strength decreases with age and is associated with reduced levels of physical activity. ${ }^{2-6}$

Protrusion of the head is characterized by increaseed flexion of the lower region cervical vertebra and upper region thoracal vertebra and increased extension of the upper cervicalis and occiput. It causes stressed anterior and posterior longitudinal ligaments, muscle tension, fatique and brachial plexus impingement., In the elderly protrusion is caused by cervical dysfunction and degeneratif spondylosis. ${ }^{2,3,7,8} \mathrm{~A}$ decrease in muscle flexibility and strength and a deformity of lower limbs will cause deviation of center of gravity (COG), so that upright posture becomes unstable and widens the base of support. Decrease in sensory and nervous system changes will affect static balance, thereby reducing the ability to do a movement such as reaching or the bending activity of daily living (ADL). ${ }^{2,3,6,9}$

In addition, the abnormal postural alignment and worse spinal mobility and flexibility make problematic the use of normal strategies for static and dynamic balance control. ${ }^{1}$

In spite of these consequences, the effect of FP on the disabling process in the elderly is poorly understood. Previous studies have given conflicting results. One study of a series of aged women referred to a bone clinic found significant associations between osteoporosis severity and some functional activities. ${ }^{10}$ Other study found that women with greater degrees of kyphosis were only slightly more likely to report back-related disability.11 Another study found that kyphosis was not associated with substantial chronic pain, disability, or poorer health in older women. ${ }^{12}$

O'Brien (1997) found a significant correlation between FP, balance and fall risk in elderly women. Postural balance disorders in the elderly will increase the risk of falls, lower physical performance and increase the difficulty to perform independently ADL and will further affect the quality of life. ${ }^{13}$ Balzini et al found the severity of FP in elderly female patients (without an apparent comorbid conditions) is related to the severity of vertebral pain, emotional status, muscular impairments and motor function with FPalso having a measurable effect on physical performance and disability. If the derangement of postural alignment is minimal, efficient compensatory strategies may be adopted to prevent disability, but when FP is more pronounced, compensatory strategies may no longer be effective, and disability may occur. ${ }^{1}$

Research of the FP with a degree of physical performance and functional status in elderly are coming from different populations outside Indonesia. The author predicts a different result if the research was conducted in Indonesia. Therefore this study was aimed to investigate the association between the severity of PF, ( standing occipital to wall distance - OWD) and physical performance (Short Physical Performance Battery - SPPB) and disability (the Barthel Index and the NADL Index) in elderly Indonesians.

\section{METHODS}

The population of this study are affordable elderly who visited the Geriatric and PMR outpatient clinic dr. Hasan Sadikin Hospital (RSHS) Bandung Indonesia. One hundred and eight elders $(60-90$ year-old) underwent the entire clinical assessment and met the inclusion criteria ie. elderly with flexion posture aged over 60 years, cooperative and willing to follow the research program, can understand commands and instructions given, limb muscle strength at least 4and signed the informed consent. The exclusion criteria are elderly with mental disorders (MMSE <23), moderate and severe depression (GDS $>10)$, visual acuity disorder which was uncorrected $(<3 / 60)$, severe hearing loss, vestibular disorders, neuromuscular disorders and severe musculoskeletal disorder such as stroke, Parkinson's disease, fracture, postural hypotension, limitation passive range of motion (ROM) of lower limbs that would affect gait patterns. All samples performed the same procedure, anamnesis, physical examination, examination of PF conducted by the authors, physical performance and 
functional status level conducted by physical medicine and rehabilitation residents in RSHS.

The severity of FP was evaluated by measuring the occipital to wall distance while subjects stood with the head in a natural position, heels and back touching a wall and knees were maximally extended (Figure 1). The severity of FP was arbitrarily classified based on the occipital-to-wall distance: mild $(<5.0 \mathrm{~cm})$, moderate $(5.1-8.0 \mathrm{~cm})$, and severe $(>8.0 \mathrm{~cm}) .{ }^{1,5}$

Clinical assessment was performed on each FP subject and included demographic (i.e. age, gender, education, marital status, occupation), Body Mass Index and clinical profile. Cognitive status was evaluated using Mini Mental State Examination. ${ }^{14}$ Presence and severity of depression was evaluated using the Geriatric Depression Scale. ${ }^{15}$

The Short Physical Performance Battery

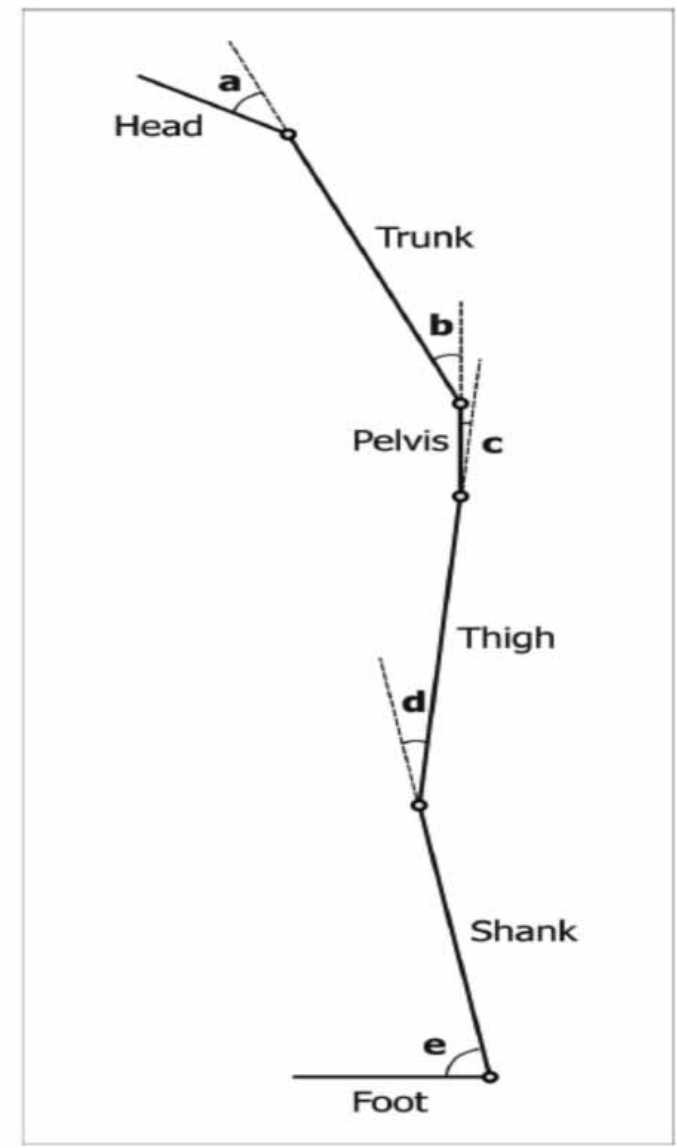

includes a three stance balance test, a 4-meter gait speed test and a five repetition chair-stand test. Each test was scored on a 0 to 4 scale, with a summary score ranging from 0 to $12 .{ }^{16}$

Disability was determined using selfreport instruments. The Barthel Index provides a score based on ratings of basic activities of daily living i.e. feeding oneself, grooming oneself, bathing, toileting, walking, climbing stairs controlling bladder and bowels with a total value ranging from $0-100 . .^{17-19}$ The Nottingham Extended Activities of Daily Living Index explores more advanced activities through four subsections: mobility, kitchen, domestic and leisure. NADL version of the 21 items with a score of four possible responses (0-3), overall score 63. Higher score indicate more independent. ${ }^{20,21}$

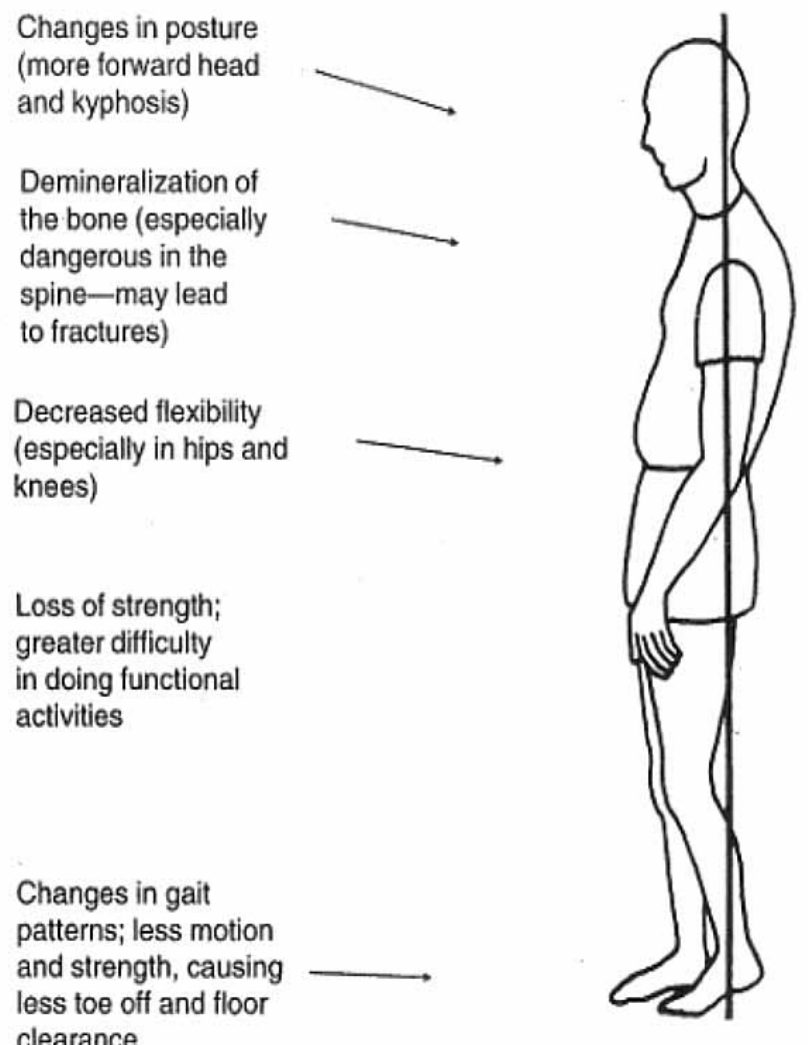

Figure 1. Postural model in elderly Lewis ${ }^{2}$ dan Benedetti ${ }^{5}$ 
Normality test of numerical data using one sample Kolmogorov Smirnov test. Analysis of variance (ANOVA) for normally distributed data and the Kruskal Wallis test for non-normally distributed data were used and Chi Square Test categorical data. The probability level for statistical significance was $\mathrm{P} \leq 0.05$ for all comparison. The data obtained were processed with SPSS version 13.0 for Windows.

\section{RESULTS}

Results showed in Table 1 indicate that the age and BMI are normally distributed ( $\mathrm{p}>$ 0.05), data were analyzed using the ANOVA parametric test . Depression scale data, MMSE, flexed posture, SPPB, Barthel index and NADL were not normally distributed $(\mathrm{p} \leq 0.05)$, they then were analyzed using the non-parametric Kruskall Wallist test

Characteristics of subjects are showed in Table 2, with mean age of subjects 72.21 (6.69), majority of subjects were women $68(63.0 \%)$. There are no significant differences in subject characteristics among the 3 groups based on gender, occupation, marital status and BMI.

The severity of flexed posture is increasing with older age ( $p$ value $\leq 0.05$ ). Increased severity of $\mathrm{PF}$ is associated with educational level in elderly with $\mathrm{p}$-value $=0.031$ ( $\mathrm{p}$ value $<0.05$ ). Furthermore those with severe FP were significantly more depressed $\mathrm{P}=0.001$ ( $\mathrm{p}$ value $\leq 0.05)$ and had lower cognitive level with $\mathrm{P}$ $<0.001$ ( $\mathrm{p}$ value $\leq 0.05$ )

Table 1. Distribution of numeric data

\begin{tabular}{|c|c|c|}
\hline \multirow{2}{*}{ Variable } & \multicolumn{2}{|c|}{ Normality Data Test } \\
\hline & $\mathrm{P}$ & Distribution Data \\
\hline Age & 0.200 & Normal \\
\hline BMI & 0.200 & Normal \\
\hline Geriatric Depression scale & $<0.001$ & Not Normal \\
\hline MMSE & $<0.001$ & Not Normal \\
\hline Flexed Posture & $<0.001$ & Not Normal \\
\hline SPPB & $<0.001$ & Not Normal \\
\hline Barthel Index & $<0.001$ & Not Normal \\
\hline DL Index & $<0.001$ & Not Normal \\
\hline
\end{tabular}

*) One Sample Kolmogorov Smirnov Test with Lilliefors Significance Correction

Table 3 shows use of the occipital to wall distance in 31 subject who were placed into the mild FP group $($ mean $+\mathrm{SE}=3.82+0.95), 50$ in the moderate $\mathrm{FP}$ group ( mean $+\mathrm{SE}=6.6+$ 0.88 ), and 27 in the severe group (mean $+\mathrm{SE}$ $=9.60+1.08)$.

Mean score of SPPB in this study was 8.35 and the median score was 8 (Table 3 ). Result of Physical performance using SPPB are summarized in Table 4. The summary score of SPPB was moderately low in moderate and severe group. Increase in the severity of FP was statistically significant reducing physical performance, $p<0.001$ ( $p$ value $\leq 0.05$ ).

Functional level status in this study (Table 3) was measured by Barthel Index mean $91.94+$ 8.85 and median 95 (65-100). The severity of FP was statistically significant (Table 4) reducing the functional status level for ADL of Barthel Index and more advanced ADL of NADL Index, $p<0.001$ ( $\mathrm{p}$ value $\leq 0.05$ ) 
Table 2. Result of Demographic, BMI, Clinical Profile Measurement

\begin{tabular}{|c|c|c|c|c|c|}
\hline \multirow{2}{*}{ Variable } & \multicolumn{3}{|c|}{ Subject Group - Severity of Flexed Posture } & \multirow{2}{*}{ Total } & \multirow{2}{*}{$\left.\mathrm{P}^{*}\right)$} \\
\hline & Mild & Moderate & Severe & & \\
\hline Age & & & & & $<0.001 * *)$ \\
\hline Means (SEs) & $67.35(5.91)$ & $72.08(5.55)$ & $78.04(6.13)$ & $72.21(6.96)$ & \\
\hline Median (SD) & $66(60-82)$ & $71.5(61-84)$ & $79(66-90)$ & $72(60-90)$ & \\
\hline Gender & & & & & $\left.0.054^{*}\right)$ \\
\hline Men & $8(20 \%)$ & $17(42.5 \%)$ & $15(37.5 \%)$ & $40(37 \%)$ & \\
\hline Women & $23(33.8 \%)$ & $33(48.5 \%)$ & $12(17.6 \%)$ & $68(63.0 \%)$ & \\
\hline \multicolumn{6}{|l|}{ Education } \\
\hline Not educated & $0(0 \%)$ & $3(6.0)$ & $1(3.7 \%)$ & $4(3.7 \%)$ & $0.031 *)$ \\
\hline Elemantary School & $1(3.2 \%)$ & $7(14.0 \%)$ & $10(37.0 \%)$ & $18(16.7 \%)$ & \\
\hline Primary High School & $8(25.8 \%)$ & $7(14.0 \%)$ & $8(29.6 \%)$ & $23(21.3 \%)$ & \\
\hline Senior High School & $11(35.5 \%)$ & $19(38.0 \%)$ & $4(14.8 \%)$ & $34(31.5 \%)$ & \\
\hline College & $11(35.5 \%)$ & $14(28 \%)$ & $4(14.8 \%)$ & $29(26.9 \%)$ & \\
\hline \multicolumn{6}{|l|}{ Occupation } \\
\hline Civil servant & $18(58.1 \%)$ & $25(44.6 \%)$ & $13(48.1 \%)$ & $56(51.9 \%)$ & $\left.0.536^{*}\right)$ \\
\hline Military & $0(0 \%)$ & $4(80 \%)$ & $7(3.7 \%)$ & $5(4.6 \%)$ & \\
\hline Business & $1(3.3 \%)$ & $6(12.0 \%)$ & $3(11.1 \%)$ & $10(9.3 \%)$ & \\
\hline Private business & $1(3.2 \%)$ & $6(12.0 \%)$ & $3(11.1 \%)$ & $10(9.3 \%)$ & \\
\hline Not working & $11(35.5 \%)$ & $9(18.5 \%)$ & $7(25.9 \%)$ & $27(25.0 \%)$ & \\
\hline \multicolumn{6}{|l|}{ Marital Status } \\
\hline Married & $31(28.7 \%)$ & $49(44.3 \%)$ & $16(21.3 \%)$ & $106(98.1 \%)$ & $\left.0.406^{*}\right)$ \\
\hline Not married & $0(0 \%)$ & $1(2.0 \%)$ & $1(3.7 \%)$ & $2(1.9 \%)$ & \\
\hline \multicolumn{6}{|l|}{$B M I$} \\
\hline Means (SEs) & 25.25 & 24.87 & 25.00 & $25.01(3.36)$ & $0.510 * *)$ \\
\hline Median (SD) & 25.70 & 24.50 & 24.7 & $24.9(17-32.5)$ & \\
\hline \multicolumn{6}{|c|}{ Geriatric depression scale } \\
\hline Means (SEs) & $1.03(1.08)$ & $1.62(1.27)$ & $2.37(1.24)$ & $1.64(1.28)$ & $0.001 * * *)$ \\
\hline Median (SD) & $1(0-3)$ & $2(0-4)$ & $2(0-4)$ & $2(0-4)$ & \\
\hline \multicolumn{6}{|l|}{$M M S E$} \\
\hline Means (SEs) & $29.26(1.15)$ & $28.16(1.78)$ & $27.30(1.40)$ & $28.26(1.69)$ & $<0.001 * * *)$ \\
\hline Median (SD) & $30(26-30)$ & $28(23-30)$ & $27(25-30)$ & $28(23-30)$ & \\
\hline
\end{tabular}

*)Chi square test $\quad * *)$ ANOVA test $\quad * * *)$ Kruskall Wallist test

Table 3. Description of Severity FP, SPPB, Barthel Index, NADL Index in elderly

\begin{tabular}{lccc}
\hline \multicolumn{1}{c}{ Variable } & Mean $(\mathrm{SE})$ & Median $(\mathrm{SD})$ & Statistic value \\
\hline Flexed Posture & & & \\
Mild & $3.82(0.95)$ & $3.7(1.8-5)$ & $31(28.7 \%)$ \\
Moderate & $6.6(0.88)$ & $6.5(5-8)$ & $50(46.3 \%)$ \\
Severe & $9.60(1.08)$ & $9.5(8.1-12)$ & $27(25.0 \%)$ \\
SPPB & $8.35(2.07)$ & $8(3-12)$ & \\
Barthel Index & $91.94(885)$ & $95(65-100)$ & \\
NADL Index & $50.09(10.56)$ & $53(12-63)$ & \\
\hline
\end{tabular}


Table 4. Relationship between the severity of FP, SPPB, Barthel Index,and NADL Index

\begin{tabular}{ccccc}
\hline Variable & \multicolumn{3}{c}{ Severity of Flexed Posture } & P*) \\
MPPB & Moderate & Severe & $<0.001$ \\
Means (SEs) & $10.58(0.95)$ & $810(1.40)$ & $6.26(1.53)$ & \\
Median (SD) & $11(8-12)$ & $8(4-11)$ & $6(3-9)$ & $<0.001$ \\
Barthel Index & & & & \\
Means (SEs) & $99.03(2.00)$ & $92.82(7.01)$ & $82.19(8.04)$ & $<0.001$ \\
Median (SD) & $100(95-100)$ & $95(65-100)$ & $80(70-95)$ & \\
NADL Index & & & $38.33(9.12)$ & \\
Means (SEs) & $59.29(2.65)$ & $50.74(8.06)$ & $39(13-53)$ & \\
Median (SD) & $60(53-63)$ & $52(12-60)$ & \\
\hline
\end{tabular}

*)Kruskall Wallist test

\section{DISCUSSIONS}

Pathological and physiological involvement of the multiple subsystems of posture and balance control may cause FP in the elderly. For this reason, all subjects underwent a clinical assessment to exclude the presence of relevant comorbid conditions. This study showed that increased severity of flexed posture is associated significantly with older age. This is consistent with study by Raffaelle et al found that age are strongly correlated with OWD. ${ }^{22}$ Ettinger et al in his research found that index of kyphosis is also increased with age. ${ }^{12}$

Majority of subjects are achieving a high school education (58.4\%) and increased a severity of flexed posture significantly associated with level of education. Higher education is expected to increase a personal knowledge to maintain health, fitness level and functional activity level and awareness to maintain proper upright posture. Freedman's study found that one of the factors that lead to functional limitations are strongly related to educational status with disabilities. Guralnik found that low education level (less than 12 years) is associated with shortened life expectancy. ${ }^{3,23}$

There were no significant differences among the 3 groups of categories i.e. gender, occupation, marital status and BMI. This study does not investigate the kind of work that may influence FP . Cailiet revealed that FP may be influenced by wrong habits in performing activities of daily living including how to do work. ${ }^{8}$ Researchers have not found a correlation between type of work FP and the kind of work. ${ }^{8}$ Most subjects in this study had a normal BMI. Malnutrition will affect level of functional fitness and activity levels in the elderly. ${ }^{6}$ Previous studies found that BMI was associated with physical function, increased disability and chronic conditions such as cardiovascular disease and osteoartritis. ${ }^{3,23}$

This study showed the majority of subjects were female $63 \%$, male $37 \%$. In general, womens life expectancy is longer than men. Data in the United States revealed that women have a life expectancy 5.3 years longer than men. ${ }^{23}$ The results of the 2000th census in Indonesia that proportion of elderly women was higher than men. ${ }^{24,25}$

This study showed that increased severity of flexed posture is associated with MMSE. Previous studies found a decrease in cognition (MMSE) in accordance with increasing degrees of severity FP. ${ }^{4}$ Cognition is a key factor to maintain the posture control in a variety of activities especially in complex tasks such as climbing stairs and have a intuition relationship with risk of falls. ${ }^{6}$

This study found that the severe group has higher scores on the Geriatric Depression Scale which means greater depression. Previous studies found subjects with severe FP were significantly more depressed and have lower motivation than the mild group. ${ }^{1}$ More severe depression may be due to disfiguration of the body or to more frequent severe neck and back 
pain, but it cannot be excluded that depression might play a role in the pathogenesis of severe FP, because depressed patients have reduced physical activity and tend to assume a more stooped posture. ${ }^{1,3}$ Depressionis characterized by apathy, loss of pleasure in activities, need greater energy to do light activities, and psychomotor retardation will reduce the functional capacity in ADL. ${ }^{3,6}$

Most subjects were categorized as having a light limitation of physical performances. A longitudinal study in the UK in 4 found a value of $<8$ as the cut-off point and was strongly correlated with problems that arise and effect the elderly. ${ }^{21}$ Guralnik found that the SPPB total score 4.5 or 6 had the possibility of disability from 4.2 to 4,9 times on the ADL and mobility than subjects with a value of 10.11 and 12 . While the value of 7,8 or 9 subject had a 1.6 to 1.8 times more likely to experience disability. ${ }^{16}$

This study found that increasing degrees of severity of PF will decrease physical performance. This is consistent with Raffaele et al. who found increased OWD will have lower physical performance, decreased balance, lower walking speed of 4 meters and sit-stand capability in elderly women. ${ }^{22}$ Balzini study found there was no significant relationship between the severity of FP with SPPB but significant results were found by examination of the Performance Oriented Mobility Assessment score which only examined balance and walking speed. Balzini concluded that it occurred resulting from an effective compensation strategy of motor control to severe malalignment. ${ }^{1}$

Balance and walking speed were found to be influenced by the amount of OWD, and this relationship could potentially be explained by changes in the biomechanical effects due to PF. In particular, the kyphosis and head protrusion caused shifting anterior COG that lead to unstable posture and a compensatory wider base of support. Lynn and Sinaki found that women with more kyphotic posture used pelvic strategy and increasing body weight to maintain balance. ${ }^{26,27}$

This adaptive strategy leads to impaired balance and consequently will increase the risk of a fall. Changes in postural control resulted in a decrease in walking speed, postural instability a real cause in "small step gait" with the characteristic decrease in step length. Impaired balance and decreased walking speed is a risk factor for falls and hip fractures that cause disability, decreased quality of life and mortality in elderly. ${ }^{6,22}$

In this study the median Barthel index score was 95, and the NADL index with median value of 53, indicating that the elderly in this study mostly had mild dependence. The severity of FP significantly decreases functional status level. These results do not correspond with Balzini research, and found a weak association between the severity of FP and disability assessed by Barthel Index. This is probably due to majority subjects in this study were regular patients who visited the Geriatric department with several comorbid factors that would affect functional activities. Balzini study showed possible bias due to that all subjects had good function to visit hospital for evaluation in Geriatric Rehabilitation hospital. ${ }^{1}$

In this study, the moderate group of FP had a mild dependence and the severe group of FP had moderate dependence. Most subjects in the moderate and severe FP had difficulties in tasks that require balance and mobility. Maintaining posture and control movement are a part of balance to perform ADL. Movement for ADL takes control of the COG in order to keep in the BOS as they move with different speeds in different directions. Activities such as transfers in the Barthel index, ornate, toiletting, bathing, walking, up and down stairing and getting dressed, requires a sitting or standing position. These activities require a lot of changes in the body's COG and spinal movements that require controlled balance on a sitting or standing position. ${ }^{6,9,28}$

We found that a severity of FP decreased the NADL index score which is consistent with Balzini's study and patients with severe FP had decreased scores on the NADL Index. ${ }^{1}$ NADL is the assessment of 'instrumental' ADL commonly used in the community, consisting of mobility, activity in the kitchen, domestic activity and hobby activities. These tasks are physically and cognitively more difficult and more complex than the activity of self- care and are necessary for the 'Independent living' in the 
elderly. These activities need greater postural control and balance than a basic ADL. ${ }^{6,17,18}$

Flexion posture led to a lack of spinal flexibility and postural rigidity. Previous studies reported a strong correlation between a loss of spinal flexibility and difficulty in climbing stairs and using public transport. Other studies showed an association between spinal flexibility with functional task i.e. reach, turning when standing and transferring from a bed to sitting ${ }^{28-31}$

We found some limitations of this study. Subjects who were recruited from an outpatient clinics of Geriatric and Physical Medicine Rehabilitation usually have at least three comorbid factors that would affect the functional activity which could be a study bias.

This study did not analyze the relationship between PF and degree of each component of physical performance and type of functional activity in the elderly. This study is a cross sectional design, so a longitudinal study is needed to evaluate contribution of FP to genesis of functional limitation and disability.

\section{CONCLUSIONS}

The severity of FP is related with decreased physical performance and decreased functional status level in elderly. Measurement of the occipital to the wall distance (OWD) can be used as a routine instrument for predicting the severity of the flexion posture in the elderly. Future studies are expected to identify contributing factors to the degree of flexion posture and functional activity in the elderly. Rehabilitation programs should consider intervention of FP to anticipate a decreasing physical performance and disability in the elderly.

\section{REFERENCES}

1. Balzini L, Vannucchi L, Benvenuti $F$, Benucci M. Clinical Characteristics of Flexed Posture in Elderly Women. J Am Geriatr Soc. 2003;51: 1419-142.

2. Lewis CB, Bottomley JM. Geriatric Rehabilitation A Clinical Approach. 3rd edition. New Jersey: Prentice Hall; 2008.

3. Guccione A. Geriatric Physical Therapy.
Philadelphia: Mosby; 2000.

4. Kisner C, Colby LA. Therapeutic Exercise Foundation and Techniques 5th edition. FA Davia. Philadelphia; 2007.

5. Benedetti MG, Berti L, Frizziero A, Presti C, Giannini S. Effects of an adapted physical activity program in a group of elderly subjects with flexed posture. Journal of Neuroengineering and Rehabilitation 5:32, Bio med Central ; 2008.

6. Bougie JD, Morgenthal AP. The Aging Body. New York: McGraw Hill; 2001.

7. Jones K, Baker K. Human Movement Explained 3rd edition. Philadelphia: Elsevier Science; 2002.

8. Cailliet R. Neck and Arm pain. 3rd edition. FA Davis Company. Philadelphia; 1991.

9. Masdeu, Sudarsky L, Wolfson L. Gait Disorders of Aging : Falls and Theurapeutics Strategies. Philadelphia: Raven-Lippincott;1997.

10. Ryan PJ, Blake G, Herd R. A clinical profile of back pain and disability in patients with spinal osteoporosis. Bone. 1994;15:27-30.

11. Ensrud KE, Black DM, Harris F. Correlates of kyphosis in older women. The Fracture Intervention Trial Research Group. J Am Geriatr Soc. 1997;45:6827.

12. Ettinger B, Black DM, Palermo L, Nevitt MC, Melnikoff S, Cummings SR. Kyphosis in older women and its relation to back pain, disability and osteopenia: the study of osteoporotic fractures. Osteoporos Int. 1994;4:55-60.

13. Kelli OB, Culham E, Pickles B. Balance and Skeletal Alignment in a Group of Elderly Female Fallers and Nonfallers. J Gerontol A Biol Sci Med Sci. 1997:52A: B221-6

14. Folstein MF, Folstein SE, McHugh PR. 'Mini-mental state'. A practical method for grading the cognitive state of patients for the clinician. J Psychiatr Res. 1975;12:189-98.

15. Yesavage JA, Brink TL, Rose TL. Development and validation of a geriatric depression screening scale: A preliminary 
report. J Psychiatr Res. 1982;17:37-49.

16. Guralnik JM, Simonsick EM, Ferrucci L, Glynn RJ, Berkman LF, Blazer DG, et al. A Short Physical Performance Battery assessing lower extremity function. J Gerontol Med Sci. 1994; 49(2):M85-94

17. Granger CV, Black T, Braun SL. Quality and outcome Measures for Medical Rehabilitation. In: Braddom RL, editor. Physical Medicine \& Rehabilitation. 3rd edition. Philadelphia; 2007.p.151-63.

18. Christiansen CH. Functional Evaluation and Management of Self-care and Other Activities of Daily Living. In: DeLisa J, Gans BM, editor. Physical Medicine \& Rehabilitation : Principles and Practice. 4th edition. Philadelphia : Lippincott Williams \& Wilkins; 2005.p.975-1004

19. Shah S, Vanclay F, Cooper B. Improving the sensitivity of the Barthel Index for stroke rehabilitation. J Clin Epidemiol. 1999;42(8):703-9.

20. Nouri FM, Lincoln NB. Anextended activities of daily Living scale for stroke patients. Clin Rehabil. 1987;1: 301-5.

21. Yohannes A. A comparison of the Barthel index and Nottingham extended activities of daily living scale in the assessment of disability in chronic airflow limitation in old age. Age and Ageing. 1997; 27: 36974.

22. Raffaele A, Pedone C, Cesari M, Di Iorio A, Bandinelli S, Ferrucci L . Relationship between the occiput-wall distance and physical performance in the elderly: a cross sectional study. Aging Clin Exp Res. 2007;19(3):207-12.

23. Halter JB, Ouslander JG, Tinetti ME, Studensky S, High KP, Asthana
S. Hazard's Geriatric Medicine and Gerontology. 6th edition. New York : McGraw Hill; 2009.

24. Darmojo RB. Teori proses menua. In: Darmojo RB, Martono H, editor. Buku Ajar Geriatri. Jakarta : Balai Penerbit FKUI; 1999.p.3-5.

25. Biro Pusat Statistik. Laporan tengah tahun BPS. Jakarta: BPS; 2000

26. Lynn MA, Sinaki M, Westerlind K. Balance Characteristics of persons with osteoporosis. Arch Phys med Rehabil. 1997;78.

27. Sinaki M, Brey RH, Hughes CA, Larson DR, Kaufman KR. Balance Disorder and Increased risk of Falls in Osteoporosis and Kyphosis: significance of kyphotic posture and muscle strength. Osteoporos Int. 2005;16:1004-10.

28. Ryan SD, Fried LP. The impact of kyphosis on daily functioning. J Arm Geriatric soc. 1997: 45:1479-86.

29. Kado D, Huang MH, Barret CE, Greendale G. Hyperkyphotic Posture and Poor Physical Functional Ability in Older Community-Dwelling Men and Women: The Rancho Bernardo Study. J of Gerontol Series A: Biological Sci and Medical Sci. 2005;60:633-7 .

30. Hirose D, Ishida K, Nagano Y, Takahashi T, Yamamoto H. Posture of the trunk in the sagittal plane is associated with gait in community-dwelling elderly population. Clin Biomech. 2004;19:57-63.

31. Kasukawa Y, Miyakoshi N, Hongo M, Ishikawa Y, Noguchi H, Kamo K. Relationships between falls, spinal curvature, spinal mobility and back extensor strength in elderly people; 2009. 
